Educational Research for Social Change (ERSC)

Volume 8 No. 1, April 2019

pp. $70-85$

ersc.nmmu.ac.za

ISSN: 2221-4070

\title{
Enriching Teaching Through Artefacts: An Early Childhood Mathematics Teacher Educator's Self-Study Project
}

Makie Kortjass

University of KwaZulu-Natal

kortjassm@ukzn.ac.za

\section{Abstract}

This paper reports on what I learned in a self-study research project, using artefacts for teaching foundation phase (FP) pre-service (student) teachers in the module, Numeracy in the Early Years. The study focused on the merits of an integrated learning approach (ILA). As a teacher educator, the self-study concept has inspired me to continually attempt to improve my educational practices with the aim of supporting pre-service teachers' learning and, consequently, their teaching. ILA requires critical awareness of how mathematical relationships are used in social, environmental, and cultural relations. I adopted a sociocultural theoretical perspective that highlights the fundamental requirement of working together in educational contexts in order to make sense of collective and personal experiences. In the artefact activity I employed, students discussed and presented self-selected cultural artefacts such as beadwork, jewellery, and clothing. This interactive activity demonstrated that pre-service teachers require ample opportunities to utilise objects from their sociocultural environments whilst gaining practical experience of the content of early childhood mathematics in order to learn about and appreciate mathematics in a meaningful way. By engaging in innovative self-study methods to support pre-service teachers, teacher educators can improve the quality of their own practice, and improve student learning.

Key words: self-study research, integrated learning approach, early childhood mathematics, cultural artefacts, pre-service teachers, mathematical knowledge for teaching (MKT)

\section{Copyright: () 2019 Makie Kortjass}

This is an open access article distributed under the terms of the Creative Commons Attribution NonCommercial License, which permits unrestricted non-commercial use, distribution, and reproduction in any medium, provided the original author and source are credited.

Please reference as: Kortjass, M. (2019). Enriching Teaching Through Artefacts: An Early Childhood Mathematics Teacher Educator's Self-Study Project. Educational Research for Social Change, 8(1), 70-85. http://dx.doi.org/10.17159/2221-4070/2018/v8i1a5 


\section{Introduction}

This article explores the use of cultural artefacts as a vehicle for understanding the integrated learning approach (ILA) for teaching mathematics in the foundation phase (PF). I am a teacher educator in the early mathematics field, and I am pursuing my doctoral studies at a higher education institution in KwaZulu-Natal. As a teacher educator, I have been concerned with improving my own teaching practice in order to enhance my students' learning. Involving FP students who were enrolled in the bachelor of education programme, I embarked on a self-study programme in the module, Numeracy in the Early Years, to explore the use of artefacts by utilising an integrated learning approach (ILA). In this article, I share my experiences and elucidate how the use of artefacts could enrich an ILA to early childhood mathematics in teacher education. As self-study teacher educators, we have a moral obligation not only to study our own educator practices, but to improve them in a way that will influence teaching practices in our primary education institutions.

During the first phase of this study, the students and I engaged in various activities in the lecture room during the eight mathematics lessons that I presented in the first semester. My primary focus was to conceptualise and operationalise an ILA. The second phase of the research involved presentations at a national conference and to a self-reflexive cohort of lecturers at the institution where I teach. In this paper, I first discuss various aspects of the teaching and learning of early mathematics using an ILA. Next, I elaborate on sociocultural theory, how it informed my thinking about my own teaching practice, and how this theory has impacted my learning. I conclude by discussing the activities that my students engaged in, the feedback I received from critical friends, and how these contributions have informed and reshaped my understanding of the use of cultural artefacts in an ILA to enhance the teaching and learning of mathematics in the FP. The study aimed to address the following research question: "How does the use of artefacts as teaching and learning aids enrich an integrated learning approach to early childhood mathematics in teacher education?"

\section{An Integrated Learning Approach in Early Mathematics Teacher Education}

Pre-service teachers need to understand that integration of the FP curriculum is key to giving substance to the bigger picture of learning (Samaras, 2011), particularly in early childhood mathematics (ECM) teaching and learning. Most pre-service teachers and teacher educators view mathematics as a subject that focuses only on cognitive aspects - but this is a fallacy that I wished to address. Given that we prepare student teachers to teach young children, we need to consider that one of the specific aims of the teaching and learning of mathematics is "to develop learners' critical awareness of how mathematical relationships are used in social, environmental, cultural and economic relations" (Department of Basic Education, 2011a, p. 8). I believe that the acquisition of mathematical skills should be fun and exciting, and that it should have a connection with the environment that learners come from. Prospective teachers should also take into consideration that young children do not experience the world as consisting of separate, different boxes such as mathematics, literacy, or life skills (National Association for the Education of Young Children, 2002). Rather, as an environment that provides holistic and integrated challenges which, in my view, is exactly what teacher educators should create. Foundation phase pre-service teachers need to be aware of the skills that build an awareness of the significant role that mathematics plays in real-life situations, and that these skills shape the personal development of the learner. Therefore, to teach mathematics effectively, teachers require insight and knowledge beyond the pages of mathematics textbooks (Pournara, Hodgen, Adler, \& Pillay, 2015). Tsamir, Tirosh, and Levenson (2011) stated that teaching early mathematics should not only include knowledge of mathematical content but also of mathematical processes. 
Adamu (2003) argued that curriculum integration is an approach that assists teachers to teach across subject areas, and to make learning reflect life. Thus, utilising this approach in teacher training enables students "to see the value of what they are being taught" (Adamu, 2003, p. 3) and understand that teaching engenders learning through meaningful connections. Schuck (2002, p. 329) argued that it is critical to understand the concepts that underpin mathematics, and that this understanding is "the first step in the appropriate and efficient use of algorithms and processes." I believe that connecting learning experiences with the environment where students and learners come from makes it easier for them to grasp mathematical concepts. Ramsay-Jordan (2017) asserted that mathematics teachers and teacher educators can influence learning by incorporating culture in mathematics teaching. Similarly, Brandt and Chernoff (2015) maintained that engaging learners in ways that will allow them to see a relationship between mathematics and their culture holds vast potential to inspire and empower learners in ways that traditional school mathematics methodologies have failed to do. It is, thus, important that the boundaries of school mathematics are extended to become more inclusive of the mathematics found in the world that learners inhabit. However, Adler, Pournara, and Graven (2000) argued that although an ILA approach is desirable and important, it places additional demands on teachers. But I argue that, to support students on their journey of discovery and development as teachers, teacher educators need to make every effort to employ creative approaches that will guide pre-service teachers to make sense of the intricacies of mathematics.

Gerdes (1998) advocated the reconstruction of teacher education programmes and curricula to reflect reality. For example, a student who was part of a liberation movement but who struggled with a mathematical problem at an institution where Gerdes conducted his research was enlightened when a real-life solution was offered to a problem (Gerdes, 1998, p. 37):

[Use] the "thumb-arm rule" to estimate distances to enemy positions: knowing the approximate height $(H)$ of the enemy position, the height $(T)$ of one's thumb, and the length (L) of the arm, one finds the distance (d) by solving the equation, $\frac{d}{H}=\frac{L}{T}$.

Nicol, Archibald, and Baker (2013) concurred, asserting that it is crucial to replace a mechanistic, compartmentalised view of teaching with a view that recognises the interconnected, holistic, and combined systems of teaching. Integrated methods of teaching facilitate the education of humans from a holistic perspective. Schuck (2002) reported how pre-service teachers indicated that learning maths in this way was beneficial, and that they wished they had been taught in this way while at school. Integrated methods could promote a deep conceptual understanding, and engender an interest in mathematics in the long run.

It is an undeniable fact that an in-depth knowledge of mathematics is key to teaching mathematics effectively. Many researchers have suggested that additional knowledges and dispositions need to be developed in mathematics teacher education (Ball, Hill, \& Bass, 2005; Grossman, 1990; Shulman, 1987). For example, Thames and Ball (2010) determined that mathematical knowledge for teaching (MKT) consists of domains that are distinguishable and defined in relation to the work of teaching. They stated that "some of the mathematical resources that teaching requires are similar to the mathematical knowledge used in settings other than classrooms" (Thames \& Ball, 2010 p. 223). Another kind of teacher knowledge that Thames and Ball (2010) referred to is common content knowledge (CCK). Mathematics in teacher education should provide pre-service teachers with contexts that are meaningful, so that they can apply their mathematical pedagogic knowledge. Moreover, Shuck and Perreira (2011) maintained that teacher educators need to create a positive and stimulating environment for pre-service teachers, and dispel their belief that mathematics is difficult. I, thus, involved pre-service teachers studying early childhood development in an ILA to explore, through 
practical experiences, how they could link mathematics with other learning areas using cultural artefacts as resources.

\section{Theoretical Perspective}

I used arts-based self-study methods that informed my sociocultural theoretical perspective and my practice of conducting self-study research (Samaras, 2010). I interacted with my pre-service teachers through active and interactive participation that involved the use of cultural artefacts. Samaras (2002) asserted that students' backgrounds, experiences, and social and cultural influences play an important part in their development. Drawing on Vygotsky's sociocultural approach (John-Steiner \& Mahn, 1996), I believe that pre-service teachers could not only acquire knowledge of mathematical content, but that their thinking, specifically through cultural stimuli, would be enhanced. They would thus be able to navigate social situations and access abstract concepts (Dimitriadis \& Kamberelis, 2006) given that perceptions are intrinsically affected by cultural and social contexts (Samaras, 2002). Linking preservice teachers' cultural experiences with mathematics content resonates with Ladson-Billings' (1995, p. 161) view that "culturally relevant teachers utilise students' culture as a vehicle for learning." By building on pre-service teachers' culture, teacher educators will learn more about themselves and their teaching practices, and they will be better equipped to support their students. The following statement by (Samaras, 2002, p. 46) echoes this sentiment:

According to Vygotsky, development can be understood as the internalisation of social activities. Past interactions and relationships with our culture-our teachers, peers, families, and communities - can tell us much about ourselves.

Correspondingly, Ladson-Billings (1995) emphasised that teachers need to encourage students to learn collaboratively and to be responsible for one another's learning. According to Dimitriadis and Kamberelis (2006, p. 193), Vygotsky was of the view that we learn through others, and that it is possible to comprehend the tools that mediate mental processes. According to Vygotsky, among these tools and symbols are systems for counting, algebraic symbol systems, conventional signs, and language (as cited in Samaras, 2010). These elements are a golden thread linking mathematics, language, and life skills in an integrative way which, in my view, obligates all teachers to employ an ILA in the classroom.

Various interpretations and applications of sociocultural approaches that highlight the importance of this perspective have been proposed (John-Steiner \& Mahn, 1996). Self-study challenges old practices of teaching, and exposes solutions to those challenges if different sociocultural approaches are employed (Samaras \& Freese, 2006). In an attempt to consider culturally responsive education as an approach to teaching, Nicol et al. (2013) argued that culturally responsive mathematics education should be conceptualised in a way that would spur the interest of students, and address their diverse needs. Therefore, both the curriculum and lesson plans should be designed to reconceptualise the relationship between pre-service teachers' experiences in their communities, and their perceptions as students (Nicol et al., 2013). Prompting students to engage with cultural artefacts will demonstrate that they can understand mathematics differently. This, in turn, may inspire them to celebrate their cultures and their communities in practical ways such as through stories, cultural values, and artefacts-vehicles of pedagogy that would unlock mathematics through environmental connectedness (Nicol et al., 2013). Teacher educators, thus, need to be mindful of the different cultural norms among their students to support their learning and, in this process, students should be encourage to exploit their own cultural tools as well as those of the learners they will one day teach (Conkbayir \& Pascal, 2016). In this context, Nicol et al. (2013, p. 76) stated: 
Culturally responsive education as an approach to teaching and learning that facilitates critical consciousness, engenders respect for diversity, and acknowledges the importance of relationships, while honouring, building on, and drawing from the culture, knowledge, and language of students, teachers, and [the] local community.

Various studies (Cimen, 2014; Gerdes, 1988; 1998; Ladson-Billings, 1995; Laridon, Mosimege, \& Mogari, 2005) have highlighted the relationship between mathematics and culture, arguing that it is important to bring these two spheres together in educational contexts. According to Nicol et al. (2013, p. 76), "improving student learning, participation and achievement are the goals of culturally responsive curriculum and pedagogy." Sociocultural theory also implies that teachers should embrace individual differences and utilise activities that accommodate those differences. Laridon et al. (2005) emphasised that sociocultural constructivism supports a pedagogy that focuses on the knowledge that students and learners bring to the classroom from their everyday experiences. Thus, teachers should pay close attention to the social and psychological tools that various cultures and backgrounds bring to the classroom.

\section{Research Methods}

The study utilised a qualitative self-study research methodology because this approach provided me with opportunities to examine my own lived practices in context. Samaras and Roberts (2011) maintained that teachers who engage in self-study research are inspired to improve their practice in order to help students improve their learning. The self is the focus in self-study research that aims to elicit understanding of one's role in influencing students' learning (Samaras, 2011). I embarked on this self-study project because I anticipated that I could gain insight on how to enhance my teaching practice, and add value to the teacher education community. Schuck and Pereira (2011, p. 5) maintained that self-study inspires us to "continually endeavour to improve our practice with the goal of supporting our students' learning and consequently their teaching of maths." The self-study research approach was appropriate because my goal was to improve my practices in preparing preservice teachers for early mathematics teaching using an ILA.

\section{Self-study research methods}

Lovin et al. (2012) encouraged the self-study approach because it assists researchers in constructing new practice-oriented knowledge and understanding through various methods that "capture the essence of the question being studied" (Samaras, 2011, p. 284). To respond to my research question, I adopted an arts-based self-study method that involved the use of cultural artefacts. This nontraditional teaching method engaged my pre-service teachers in a novel yet interactive learning methodology.

\section{Arts-based self-study method}

According to Samaras and Freese (2006, p. 73), an arts-based self-study methodology "promotes and provokes self-reflection, critical analysis, and dialogue about improving one's teaching through the arts." This approach assures connections between the self and the practices that are being employed. Weber (2014) noted that the inquiry process of arts-based self-study research is also a style of teaching, and Samaras (2010) asserted that using the arts effectively in teaching makes much sense. I believe that an arts-based approach may transform teaching and enhance the knowledge and insight of pre-service teachers as cultural objects and artefacts become tools that engender deeper understanding of abstract topics in mathematics. I utilised the creation of a collage as an arts-based method to articulated my thoughts and understanding of my students through visual images. 


\section{Utilising cultural artefacts}

Self-study research has evolved, and offers researchers opportunities for dynamic research methods. Dhlula-Moruri, Kortjass, Ndaleni, and Pithouse-Morgan (2017, p. 81) noted that "one of the more innovative research methods used in self-study research involves working with objects or artefacts, which can be understood as objects that have a particular personal, sociocultural or historical significance." Similarly, Mitchell (2011) highlighted rich possibilities for working with objects and artefacts as visual stimuli in social science-most of these objects enriched meaning and aided research. Glenn and Hayes (2007, as cited in Mitchell, 2011, p. 39) affirmed that "just as we are collectors of things, things are collectors of meanings." A human-made object is normally one of cultural or historical interest. Allender and Manke (2008) were of the view that the study of artefacts uncovers what the products that constitute our material culture symbolise, and what occurs in the world we live in. Using artefacts brings strong images, memories, and feelings to mind (Allender \& Manke, 2008), which is why mathematics teachers should use support materials such as physical objects and artefacts to introduce and reinforce concepts. It was against this backdrop that I conducted the study.

\section{Creating a collage}

A collage is an effective visual interpretive tool that expresses ways of knowing and understanding, and makes ideas and new sights explicit (Butler-Kisber \& Podma, 2010). According to van Schalkwyk (2010, p. 678), "the collage is a poster or visual representation in which the participant makes use of photos, pictures and cuttings (also text) from magazines and other media" to portray phenomena. Collages represent situations or events and feelings to tell a story or to illustrate a concept. Creating a collage provides a means of articulating what is said, and even what is not said, and allows for numerous paths of interpretation and for the accessibility of abstract concepts (Butler-Kisber, 2008). A collage may motivate intrapersonal conversations with oneself in order to improve a particular practice or idea. For example, I created a collage to reflect on my interpretation and analysis of the data generated in my study.

\section{Participants}

I coordinate and teach the Numeracy in the Early Years module in the first semester at the institution where I lecture. The study involved two groups of student teachers. Of the 114 students in the population group, I worked with a sample group of 58 students, comprising 55 black and three Indian students (18 men and 40 women).

\section{Ethical considerations}

Ethical issues are critical when conducting research. Ellis (2007) pointed out that ethical issues are complex, and that no general principle applies to all cases. In self-study research, as we endeavour to improve our practice, "it is our obligation and responsibility to ensure that, in the process of researching, we do not bring harm to others-to students, families, colleagues, or the school community" (Samaras, 2011, p. 145). I followed proper procedures as guided by the university's ethics policy. All the pre-service teachers who participated in the study signed consent forms that explained the purpose of the study and the usefulness of their contributions to the study. The ethical issues were discussed with the students before they completed the consent forms. Approval to conduct this study was obtained from the institution and ethical clearance was granted to conduct the study. 


\section{Data Generation}

All 114 pre-service teachers mentioned above participated in the eight lessons that focused on ILA. One of the lessons I presented focused on the content area of patterns, functions, and algebra in mathematics. The aim of this lesson was to show how teachers could assist learners to discover and be aware of the patterns around them-patterns in nature, in cultural artefacts, and in everyday life. The lesson was linked with the Curriculum Assessment Policy Statement (CAPS) topic, Geometric Patterns (Department of Basic Education, 2011b), because I deemed it important to demonstrate to students how, as fully fledged teachers, they should be able to facilitate the curriculum.

After this lesson, the students were asked to each bring a cultural artefact to class. I showed them the artefact that I had selected (Image 1) as an example to stimulate their ideas on how they could link mathematics, language, and life skills using cultural artefacts. My artefact was a place mat made of grass called ikhwani. Grass is woven into a rope and stitched into a circle to make this type of mat. In many African communities, a hot plate would be placed on such a grass placemat to protect the table. We discussed the mathematical link: a geometric, circular pattern that extended naturally from the inner centre to the outer circle in shaping the place mat. I demonstrated how, in terms of language, new vocabulary could be applied and acquired, for example, ikhwani is a type of grass used to make place mats, floor mats, brooms, garden chairs and tables, and so on. The students were excited, and understood that their future learners could do craft work as part of the life skills learning area, and that the creative arts approach might be employed to develop their learners as creative, imaginative individuals with an appreciation of the arts (Department of Basic Education, 2011a). It was also a revelation that mathematics was applicable to their cultural environments, and that the ILA could be employed as a creative and exciting teaching methodology (Gerdes, 1998).

Image 1: A place mat made of ikhwani

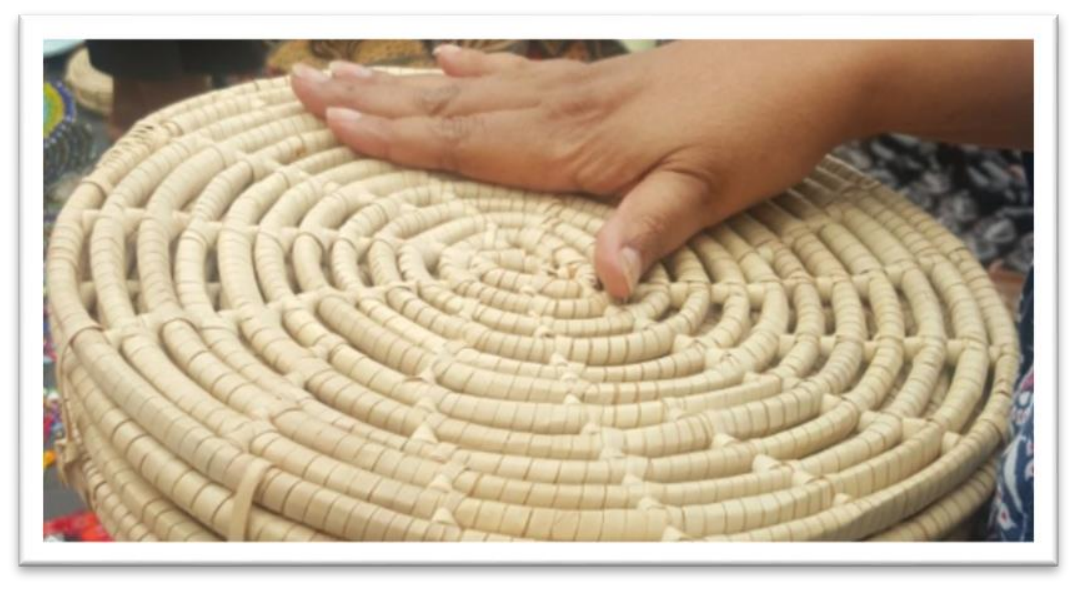

For the artefact activity, the students had to present and discuss the various artefacts they had selected and brought to class. I divided the students into six groups and asked them to select two artefacts that they were going to discuss and present to the class. This allowed the students to work collaboratively. Teamwork resonates with the sociocultural way of teaching because it embraces the power of working together.

The artefacts the students selected included beadwork, jewellery, and textiles. They were asked to describe the selected artefact, examine the pattern on each, and discuss how it linked with mathematics, language, and life skills. The purpose was to provide students with the opportunity to think about and articulate their understanding of the use of cultural artefacts for teaching according to an ILA. I was mindful of Adamu's argument that "learning is believed to occur faster and more 
thoroughly when it is presented in meaningful contexts, with an experiential component" $(2003$, p. 4) as I underpinned my teaching, and encouraged my students' learning, through connections to real life.

Image 2: Isigege [ceremonial garment]
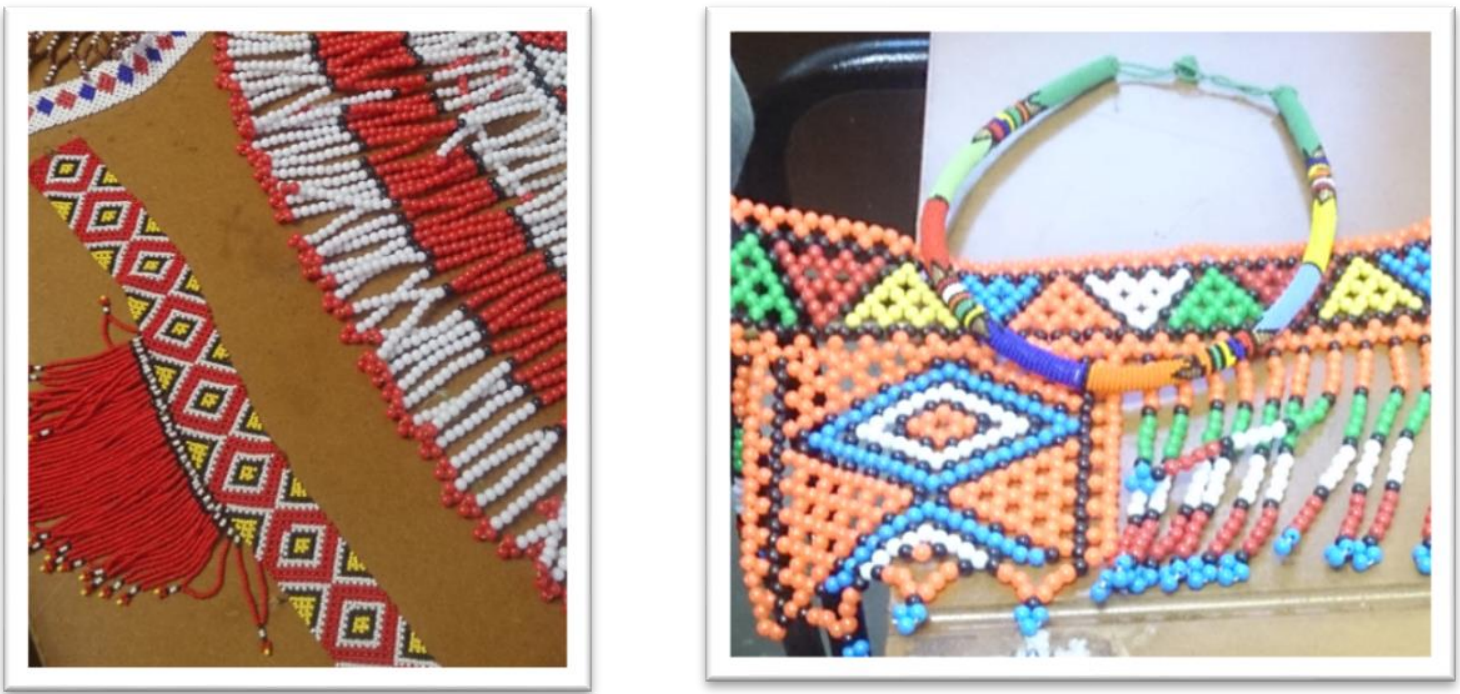

One group presented the garment known as isigege (Image 2). This item is normally worn by young girls, especially during ceremonial occasions in the Zulu culture. The garment is beaded in various colours. The students linked this object to mathematics by referring to the different shapes such as circles and triangles and the patterned colours. Number skills were also highlighted as they argued that these skills could be developed by counting the number of colours and the number of different shapes, and learning about basic geometric shapes could also be visually enforced. They also noted that the garment could assist vocabulary enrichment by using and learning words to describe the patterns, listing the colours, or telling stories about the artefact. They mentioned that learners could develop handwork skills in the life skills learning area by being given the opportunity to string beads and create their own artefacts as part of the creative arts programme. They also mentioned that learners could learn about traditional Zulu events such as umemulo [coming of age ceremony] and umkhehlo [prewedding ceremony].

Image 3: Eastern necklace

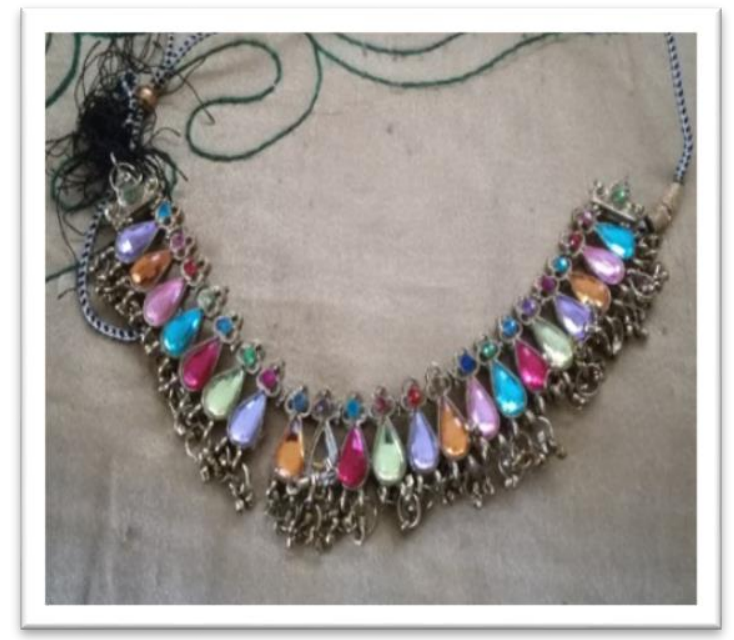

The object depicted in Image 3 is a necklace that is typical of the jewellery worn by Indian brides on their wedding day. Its pattern is repeated in teardrop and floral shapes. Links were made with 
mathematics through the geometric patterns and the different colours that follow a certain sequence. The students argued that learners could acquire new vocabulary and the correct spelling of words such as jewellery, Eastern, and necklace. It was mentioned that knowledge of, and respect for, different cultures were also represented by this traditional piece of jewellery given that learners could learn about the Indian culture in the life skills learning area.

\section{Image 4: Ucu [symbol of love]}

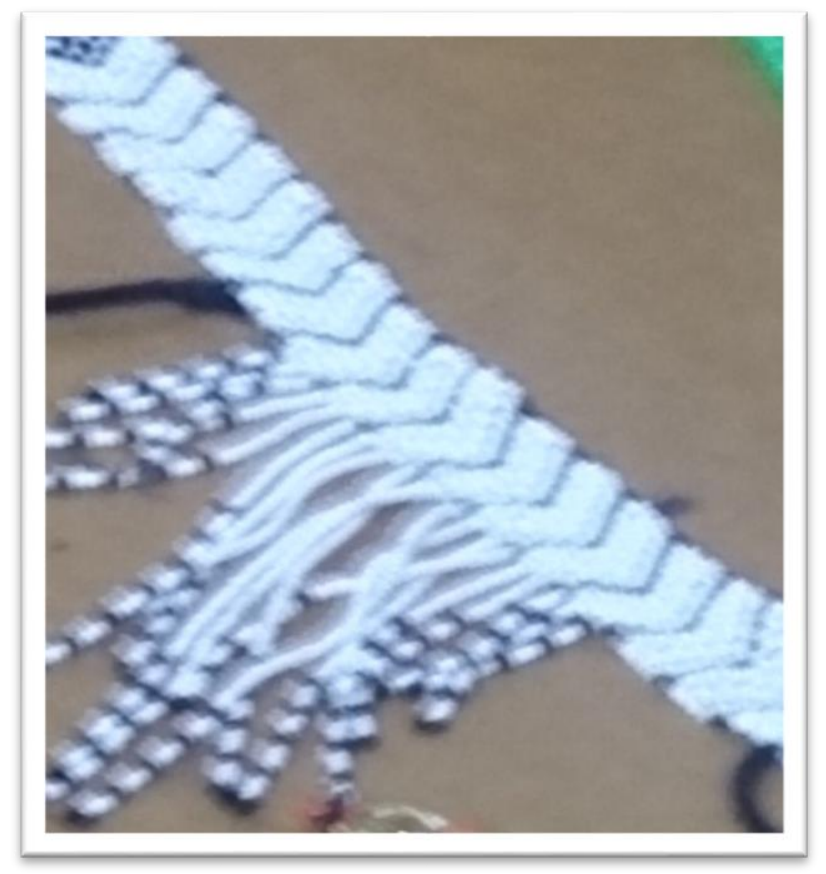

The artefact depicted in Image 4 is an ucu-a symbol of love. When a young woman gives an ucu to a young man as a sign of her love, this marks the start of a relationship between them. The string of white beads in a pattern that is trimmed with a blue braid epitomises mathematics. Explanations or stories related to the significance of the $u c u$ also relate to the language learning area, and an understanding of Zulu beadwork that contains hidden messages is important in the life skills programme. For example, learners could learn that white is a symbol of love and purity. Black beads are rarely used in an ucu because black is the colour of sorrow and despair-but when it is combined with blue and white, it is a symbol of marriage. The students thus understood how understanding the colour combinations in Zulu beading is important for cultural bonding and the building of relationships.

Image 5: Pre-service teachers' cultural artefacts
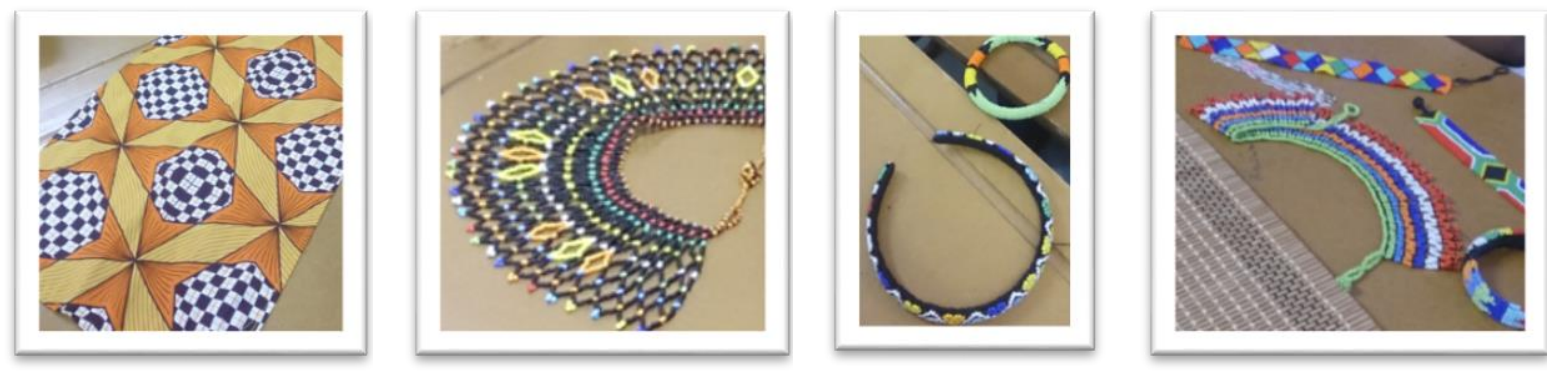

Other cultural artefacts that were presented by the students are depicted in Image 5 . These objects included textiles, necklaces, and bracelets that people wear during traditional African events. The students understood that by exploring the shapes and meanings of these artefacts, they went on a journey of exploring how people interact with them every day of their lives. This experience 
acknowledged culturally responsive mathematics education, which is a way to address the diverse needs and interests of students (Nicol et al., 2013). After the discussions of the artefacts and using them as examples of how to teach through an ILA, the students began to open their minds to new ways of teaching and learning.

\section{Data Analysis}

Various data sources were used to inform this study, such as transcriptions of students' artefact presentations, my journal entries, classroom observations, and transcriptions of critical friends' comments and suggestions. I used all these notes to create a collage that assisted me in making meaning of the data. Butler-Kisber and Poldma $(2010$, p. 2) appropriately described my engagement with the data:

These new, arts-informed modes of inquiry mediate different kinds of understandings grounded in direct experiences ... expand the possibilities of diverse realities ... increase voice and reflexivity in the research process ... and create more embodied and accessible research results.

The generated data allowed me to gain an in-depth perspective on the process of analysis and interpretation of the data, and I was able to classify and categorise the data according to themes. In the following section, I explain how I utilised the inductive approach to address my research question. I also elucidate how I made use of a collage to make sense of my data. Image 6 below depicts the collage I created in my effort to make sense of the data.

Image 6: Author's collage

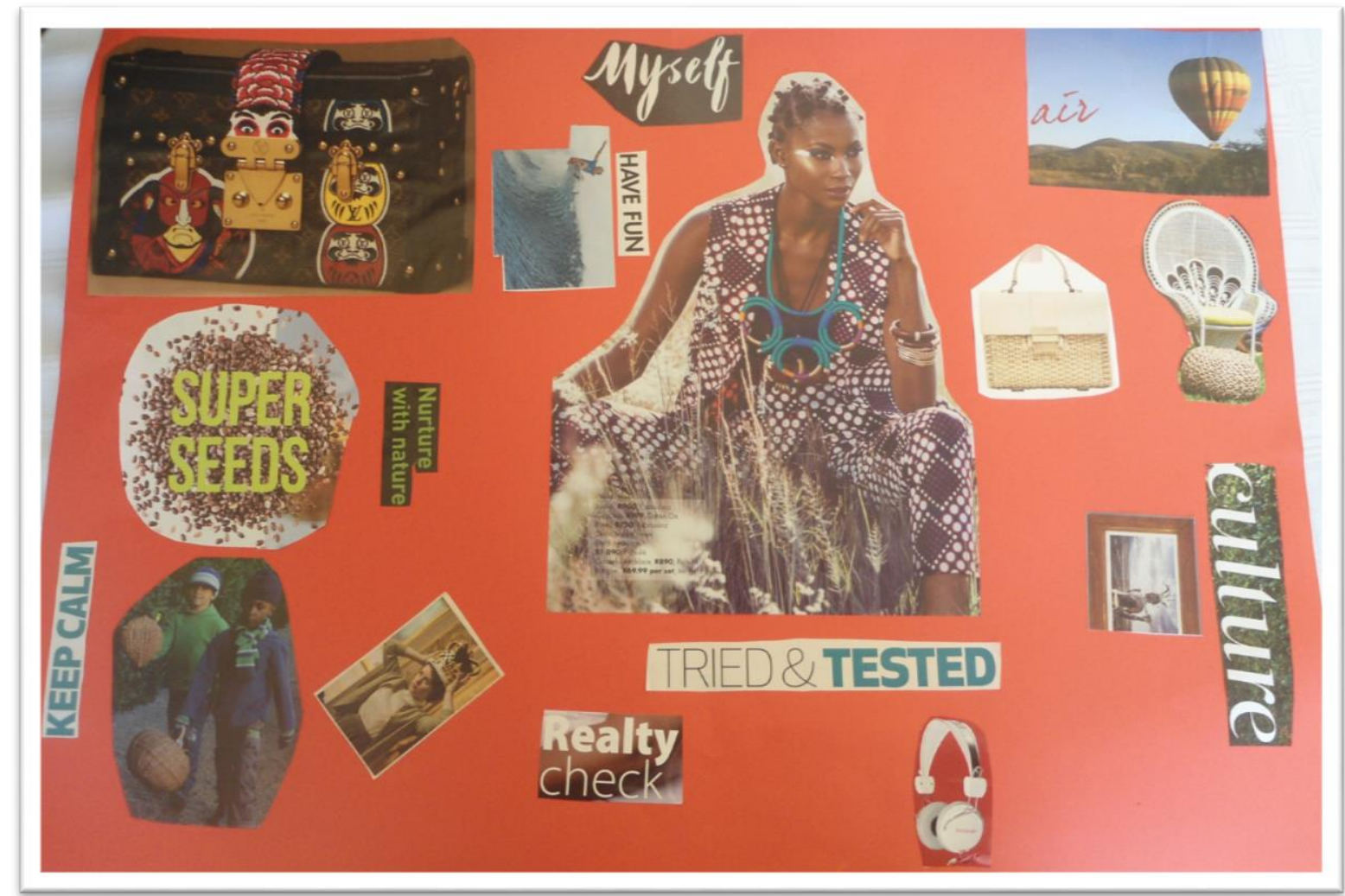

I analysed my data by employing the inductive approach pertaining to the learning zones as proposed by Vygotsky's zone of proximal development (ZPD), where diverse people from different communities 
collaboratively share and facilitate learning (Samaras, 2011). A zone of possibility exists when teachers and students learn together, and are receptive to what they can accomplish collaboratively (Samaras, 2011). In this study, I wanted to understand what I was learning from my experiences with the students in order to improve my practice. I read and reread the transcripts and reflected on what I was learning about my students and my role as a teacher educator. The collage I created assisted me in discovering what I was learning through a process of "zooming in and zooming out" (Chang, 2008, p. 128). According to Butler-Kisber and Poldma (2010), visual inquiry is used to generate insights, and to understand phenomena. I used the collage reflectively, and focused on the question of how working with artefacts could enrich an ILA to early childhood mathematics in teacher education. Using the collage in this manner evoked novel ideas and revealed new connections and understandings that had previously been unexplored (Butler-Kisber \& Poldma, 2010). I recorded my ideas, highlighted possible patterns, and identified emerging themes and connections. For example, I was able to explain how the collage in Image 6 helped me to understand the work I had done with my students, and to identify the milestones we had reached. One notation illuminated the success that we as a team were beginning to achieve when I understood the metaphor of the falling seeds in Image 6. My notation reads:

The visual image of the seeds, with the caption "super seeds," makes me understand what I was learning about the students' performance in the module. I was worried at the beginning, but their improvement in the second assignment and the portfolio they developed gave me confidence that the seeds were falling on fertile ground. They would smile and be relaxed, make fun.

I am trying this new approach and learning in the process. I am aware of the challenges, and how I will do things differently in the future. I am motivated by how the student teachers are responding to the activities and this gives me hope that one day they will model this approach for the benefit of their future learners.

\section{Engagement With Critical Friends}

As a novice researcher and a doctoral candidate, I am constantly learning through my interaction with colleagues and other self-study researchers. One lesson I learned is to never be afraid of constructive criticism, particularly when it is offered by a critical friend. According to Schuck and Russell (2005), critical friends offer support and practical ideas that are needed for one's development. Similarly, Samaras (2011) noted that learning occurs through interactions with critical friends who contribute to and enhance one's research. It is therefore immensely important to make use of such a support system in self-study research.

I presented my research to two different groups of researchers and teacher educators - at a national conference that had been organised by the South African Association of Early Childhood Education (SARAECE), and at a reflexive self-study group at my institution. I deeply value the feedback that I receive from my colleagues in the role of critical friends while my work is in progress (Kortjass, 2019), and I shall value their inputs for a very long time. Loughran (2004) contended that a major benefit of self-study research is that it encourages collaboration with others. Schuck (2002) also stated that the role of critical friends is important in assisting the researcher with the checking and interpretation of the data, while Feldman (2003) maintained that teacher educators need to ensure that they are not blinded by the manner in which they create their stories, and that they should take note of feedback from critical friends. I therefore monitored my research by referring it to critical friends who offered different viewpoints and perspectives that challenged and strengthened my work.

\section{Learnings}


During my research journey, I observed that my students became excited and enjoyed learning about how mathematical concepts could be illuminated through their interaction with artefacts. I discovered that they were also able to link mathematics with language and life skills when they presented their artefacts. And, they were able to associate mathematics with the real world and their own life experiences. However, I realised that I had to guide them to open their minds and to focus more on mathematics and less on the traditional aspects of the artefacts they presented. In this process, my own mind became clear about the amount of work and the time required to plan every approach that is used in the classroom-whether it involves pre-service teachers or FP learners. Moreover, by exposing my work to critical friends, I was offered different and rewarding new perspectives on my own skills as a teacher educator.

My attempts to answer the research question: "How does the use of artefacts as teaching and learning aids enrich an integrated learning approach to early childhood mathematics in teacher education?" were rewarding and positive and enabled me to illuminate themes from the collage I had created. I was in awe of the findings because they were not intricate or highly academic, but reflected that natural common sense and perseverance are keys to successful teaching: have fun, have something to hold on to, nurture with nature, keep calm, and do reality checks.

The theme "have fun" emerged from the fact that I wanted the students to enjoy engaging with mathematics. This was important for me at the time because mathematics is generally referred to as "a difficult subject" that is "abstract and not enjoyable." Many of my students had had negative experiences with mathematics and were, therefore, not positively inclined towards my classes from the beginning. They had made comments such as "We do not like mathematics" and "We came to do foundation phase because the maths here is not difficult." I knew it would be crucial to challenge these FP students given that not only did they have to acquire skills to teach mathematics to learners in the FP, but they needed to be equipped and knowledgeable as teachers. I was delighted when my efforts to achieve this goal by using artefacts in an ILA seemed to be fruitful.

The tangibility and presence of these artefacts evoked meaning and feelings and prompted interaction and engagement in a way that something more abstract could not do. Everybody could relate to the artefacts because they could see and touch them and tell stories about them and, in this way, they were empowered to understand how the integrated learning approach functions. I was also made aware of the potential conflict that might arise in our classrooms about culture, which is always a sensitive issue. Questions such as: "What is culture?" and "Whose culture are we talking about?" made me aware of the challenges I might come across when dealing with issues of culture. Doing something new, such as exploring object inquiry and using arts-based methods, may stimulate feelings of vulnerability. I have noted elsewhere (Kortjass, 2019) that when one abandons one's comfort zone, onelearns from a position of vulnerability even though it can be frightening.

The theme "keep calm" emerged from my feelings and understanding when I received feedback from my critical friends. For example, one person felt that the lesson on artefacts might prioritise particular cultural heritages. She said:

Something that troubles me is when you have limited cultural diversity. You have your students from the Zulu culture and the Indian culture and they have a very strong cultural heritage. But if there were coloured students like myself, or white students, what would they have brought?

This comment tempted me to feel defensive, but I calmed down and focused on the feeling of discomfort, which gave me the impetus to listen. I learned that I needed to listen carefully to what my 
critical friends were saying in order to improve my practice. This comment encouraged a new perspective and I realised I should ensure that all my students are included in the lessons I present in the future. A positive comment from another critical friend stated that she liked the self-study aspect "as a layer on top" of what I had been doing. This comment suggests that the cultural perspective might be a good approach to accommodate the cultures that were ignored previously. She affirmed her comment as follows:

There is more appreciation for the artefacts that are still alive for various cultures and those that need to be brought in. Because, if we look at our classrooms and our learners, the children's context, they are diverse. So in terms of you as a teacher educator preparing for these kind of things, whether you are Indian, or black, or coloured, you actually, generally, have a set of diverse learners that you are teaching.

I thus learned that there needs to be appreciation for all cultures. Cultural sensitivity does not mean inclusion or exclusion, but it is trying to bring them all together. Some artefacts just appeal to you as a teacher educator or a student, so these are quite important. It was in this context that the theme in the caption "reality check" resonated with me during the feedback from my critical friends. I learned to listen to comments and to take them to heart, and I learned that I need to check my motives and practices consistently in order to practise what I preach. As a teacher educator involved in self-study research, I acknowledge and accept that I am in a delicate position, both as a researcher and a as teacher who works with students for an entire semester (Samaras, 2011, p. 150). I need to be aware of my different roles in order to be genuine in the construction of my understanding and my discoveries.

I value the insights that I gained from working with pre-service teachers in activities involving cultural artefacts. For example, I learned how important and symbolic an Eastern necklace is to an Indian bride. I uphold my Vygotskian style by being open to collaborative learning with my students. Planning activities that enhance students' creativity is fundamental and requires hard work. Therefore, I need to plan future lesson activities well in advance. I am also aware that culture is now interpreted in many ways by modern young people. I shall need to think carefully about culture and engage in conversation with students of all races about what culture means to them.

I learned to be open-minded when it comes to receiving criticism from colleagues. I understand now how critical friends "can broaden each other's zone of possibility in understanding their practice" (Samaras, 2011, p. 77). Schuck and Russel (2005, p. 13) stated that "critical friendships are valuable if they encourage us to reconsider [the] aims and purposes of practice and create the space and opportunity ... to be nourished." The discussions with critical friends gave me another way of looking at myself, and the work I do. If I am down and overwhelmed by the magnitude of the tasks I set myself, I am still able to rise like a balloon, have a look at what I have accomplished or what I have missed, and try again.

\section{Strengths and limitations}

The process of participating in self-study research is not as easy as it may appear. It entails questioning and challenging yourself, visiting and revisiting what you are discovering, openness and deep reflection. But it is always rewarding. It was important to be cautious in the classroom when the students got carried away during their presentations about cultural artefacts, tending to focus on traditional aspects and not on linking mathematics with other learning areas. But on a positive note, their ability to recognise and apply mathematical concepts based on diverse cultural objects was inspiring. I am now convinced that alternative ways of learning mathematics will stimulate the interest 
of teacher educators and students, which augurs well for the teaching and learning of mathematics in the future.

\section{Conclusion}

My study has demonstrated that interacting with students and connecting with them in a sociocultural way to learn about an ILA to early mathematics education for teacher educators and student teachers was invaluable. The key lesson I learned from this study is that positive experiences of learning are generated through employing an integrated learning approach using actual objects that the students can relate to. This approach has significant implications for the teaching and learning of mathematics in the FP given that it can be fun and challenging at the same time. Evidently, the artefacts that were used were pivotal in this study as, without them, the students' understanding of the ILA would not have been enriched.

The study approach facilitated the students' participation and diverse inputs and stimulated their ability to link artefacts with mathematics education and other learning areas. This innovative approach was liberating because it engendered a different outlook on, and provoked exciting prospects for, the teaching and learning of mathematics in these students' classrooms one day. Moreover, teacher educators may feel at ease about involving their students in a variety of innovative methods in order to guide them to understand and like mathematics teaching and learning. The findings of this selfstudy research project, which utilised an arts-based approach, are thought provoking and will hopefully inspire other teacher educators to utilise similar methods. I hope this study will provide teacher educators with insights into ways in which early mathematics in teacher education can assist student teachers' understanding of the cultural influences that bear on the teaching approaches they will use in their future teaching practice (Schuck, 2009). While acquiring mathematics learning from artefacts is well recognised, it is important to build it into pre-service teacher education programmes. The study will also contribute to research about collaborative teaching and learning. The presence of colleagues who act as critical friends is important in the development of an authentic self-study because their contributions enhance the reflective nature of such studies. Unfavourable comments may not be pleasant, but they must be viewed as a learning opportunity, and I shall continue to share my work as it evolves because this helps me grow as a teacher educator.

\section{References}

Adamu, A. U. (2003, March). The concept of curriculum integration: Its meaning, scope and modalities. Paper presented at the Workship on Integrating Qur'anic Education, Arewa House, Kaduna, Nigeria.

Adler, J., Pournara, C., \& Graven, M. (2000). Integration with and across mathematics. Pythagoras, 9(53), 2-13.

Allender, J., \& Manke, M. P. (2008). Evoking self in self-study: The analysis of artifacts. Journeys of hope: Risking self-study in a diverse world, 14(6), 20-23.

Ball, D. L., Hill, H. C., \& Bass, H. (2005). Knowing mathematics for teaching: Who knows mathematics well enough to teach third grade, and how can we decide? American Educator, 2005(Fall), 14-46.

Brandt, A., \& Chernoff, E. C. (2015). The importance of ethnomathematics in the math class. Ohio Journal of School Mathematics, 71, 31-36.

Butler-Kisber, L. (2008). Collage as inquiry. In A. L. Knowles \& L. Cole (Eds.), Handbook of the arts in qualitative research (pp. 265-276). Thousand Oaks, USA: SAGE. 
Butler-Kisber, L., \& Poldma, T. (2010). The power of visual approaches in qualitative inquiry: The use of collage making and concept mapping in experiential research. Journal of Research Practice, 6(2), $1-16$.

Chang, H. (2008). Analyzing and interpreting data: Autoethnography as method. Walnut Creek, USA: Left Coast Press.

Cimen, O. A. (2014). Discussing ethnomathematics: Is mathematics culturally dependent? ProcediaSocial and Behavioral Sciences, 152, 523-528.

Conkbayir, M., \& Pascal, C. (2016). Early childhood theories and contemporary issues: An introduction. London, UK: Bloomsbury.

Department of Basic Education. (2011a). Curriculum and assessment policy statement Grades R-3: Life skills. Pretoria, South Africa: Government Press.

Department of Basic Education. (2011b). Curriculum and assessment policy statement Grades R-3: Mathematics. Pretoria, South Africa: Government Press.

Dhlula-Moruri, M. N., Kortjass, M., Ndaleni, T., \& Pithouse-Morgan, K. (2017). A stove, a flask, and a photograph: Learning together through object inquiry in self-study research. In D. Pillay, K. Pithouse-Morgan, \& I. Naicker (Eds.), Object medleys: Interpretive possibilities for educational research (pp. 81-98). Rotterdam, Netherlands: Sense.

Dimitriadis, G., \& Kamberelis, G. (2006). Theory for education. New York, USA: Routledge.

Ellis, C. (2007). "I just want to tell my story": Mentoring students about relational ethics in wrting about intimate others. In N. K. Denzin \& M. D. Giardina (Eds.), Ethical futures in qualitative research: Decolonizing the politics of knowledge (pp. 209-227). Walnut Creek, USA: Left Coast Press.

Feldman, A. (2003). Validity and quality in self-study. Educational Researcher, 32(3), 26-28.

Gerdes, P. (1988). On culture, geometrical thinking and mathematics education. Education Studies in Mathematics, 19(2), 137-162.

Gerdes, P. (1998). On culture and mathematics teacher education. Journal of Mathematics Teacher Educational, 1, 33-53.

Grossman, P. L. (1990). The making of a teacher: Teacher knowledge and teacher education. New York, USA: Teachers College Press.

John-Steiner, V., \& Mahn, H. (1996). Sociocultural approaches to learning and development: A Vygotskian framework. Educational Psychologist, 31(3/4), 191-206.

Kortjass, M. (2019). Reflective self-study for an integrated learning approach to early childhood mathematics teacher education. South African Journal of Childhood Education, 9(1), 1-11.

Ladson-Billings, G. (1995). But that's just good teaching! The case for culturally relevant pedagogy. Theory into Practice, 34(3), 159-165.

Laridon, P., Mosimege, M., \& Mogari, D. (2005). Ethnomathematics research in South Africa. In D. R. Vithal, J. Adler, \& C. Keitel (Eds.), Researching mathematics education in south africa: Perspectives, practices and possibilities (pp. 133-160). Cape Town, South Africa: HSRC Press.

Loughran, J. J. (2004). A history and context of self-study of teaching and teacher education practices (Vol. 1). Dordrecht, Netherlands: Kluwer.

Lovin, L. H., Sanchez, W. B., Leathan, K. R., Chauvot, J. B., Kastberg, S. E., \& Norton, A. H. (2012). Examining beliefs and practices of self and others: Pivotal points for change and growth for mathematics teacher educators. Studying Teacher Education, 8(1), 51-68.

Mitchell, C. (2011). Doing visual research. London, UK: Thousand Oaks: SAGE. 
National Association for the Education of Young Children. (2002). Early childhood mathematics: Promoting good beginnings. Joint position statement of the National Association for the Education of Young Children (NAEYC) and the National Council of Teachers of Mathematics (NCTM). Adopted 2002, updated 2010.

Nicol, C., Archibald, J., \& Baker, J. (2013). Designing a model of culturally responsive mathematics education: Place, relationship and storywork. Mathematics Education Research Journal, 25, 73-89. doi:10.1007/s13394-012-0062-3

Pournara, C., Hodgen, J., Adler, J., \& Pillay, V. (2015). Can improving teachers' knowledge of mathematics lead to gains in learners' attainment in mathematics? South African Journal of Education, 32(5), 1-10.

Ramsay-Jordan, N. N. (2017). Examining the integration and use of culturally responsive mathematics pedagogy in preservice teachers reflections and practice: Implications for black children (Doctoral dissertation, Georgia State University). Retrieved from https://scholarworks.gsu.edu/cgi/viewcontent.cgi?article=1051\&context=mse_diss

Samaras, A. P. (2002). Self-study for teacher educators: Crafting a pedagogy for educational change. New York, USA: Peter Lang.

Samaras, A. P. (2010). Explorations in using arts-based self-study methods. International Journal of Qualitative Studies in Education, 23(6), 719-736.

Samaras, A. P. (2011). Self-study teacher research: Improving your practice through collaborative inquiry. London, UK: SAGE.

Samaras, A., \& Freese, A. (2006). Self-sudy of teaching practices. New York, USA: Peter Lang.

Samaras, A., \& Roberts, L. (2011). Flying solo: Teachers take charge of their learning through self-study research. Learning Forward, 32(5), 42-45.

Schuck, S. (2002). Using self-study to challenge my teaching practice in mathematics education. Reflective Practice, 3(3), 327-337.

Schuck, S. (2009). How did we do? Beginning teachers teaching mathematics in primary

schools. Studying Teacher Education, 5(2), 113-123.

Schuck, S., \& Pereira, P. (2011). What counts in mathematics education? In S. Schuck \& P. Perreira (Eds.), What counts in teaching mathematics: Adding value to self and content (pp. 1-9). New York, USA: Springer.

Schuck, S., \& Russell, T. (2005). Self-study, critical friendship and the complexities of teacher education. Studying Teacher Education: A Journal of Self-Study of Teacher Education Practices, 1(2), 107-121.

Shulman, L. S. (1987). Knowledge and teaching: Foundations of the new reform. Harvard Educational Review, 57, 1-22.

Thames, M. H., \& Ball, D. L. (2010). What math knowledge does teaching require? Teaching Children Mathematics, 17(4), 220-229.

Tsamir, P., Tirosh, D., \& Levenson, E. (2011). Windows to early childhood mathematics teacher education. Journal of Mathematics Teacher Education, 14, 89-92.

van Schalkwyk, G. J. (2010). Collage life story elicitation technique: A representational technique for scaffolding autobiographical memories. The Qualitative Report, 15(3), 675-695.

Weber, S. (2014). Artsbased self-study: Documenting the ripple effect. Perspectives in Education, 32(2), 8-20. 